\title{
Application of green intelligent energy-saving building materials in modern architecture
}

\author{
ZhiNeng Tong \\ Jiangxi Normal University of science and technology, China
}

\begin{abstract}
Keywords: Green materials; Building energy efficiency; Green building.
Abstract. The application of energy-saving materials in construction should maximize the conservation of resources, minimize the impact of the environment, health and comfort oriented, to achieve "people, nature, construction" of the three harmonious unity of the building. In this paper, the application and development of green, intelligent and energy-saving building materials in roofing, wall, door and window and other aspects are expounded systematically and detailedly.
\end{abstract}

\section{Introduction}

With the development of society, the progress of science, people demand for their quality of life is more and more high, very apparent in the people for the selection of building materials, in the past we often choose some cheap, sturdy building materials, now we have added on the basis of green building materials the requirements of. Because green, intelligent building materials can greatly enhance people's quality of life.

\section{Green intelligent building materials}

Green building refers to the intelligent materials, those who take the raw materials in the process of product use and manufacturing for the minimum load of the earth, can self adapt to changes and more conducive to human health materials, called the material green intelligent building.

\section{Main features of green materials}

Green material manufacturing process, green materials are generally used natural resources for survival, such as: some living and construction waste and other waste.

In the manufacturing process is mainly in order to guarantee for the environment has no side effect to production, so we need to ensure that no harm to human body material retained in the process of manufacturing and production.

Green building materials are designed for the health of the human body. The theme of green building materials is designed to ensure people's living environment and building safety, in order to strengthen people's living environment.

Green building materials are not used only once, and it can be recycled.

\section{Classification of green materials}

For the classification of building materials, we classify them mainly on the basis of their efficacy and fall into three categories:

Air cleaning category. As the name suggests, building materials such as air purification can allow people to enjoy the fresh air in the many environments of PM2. 5 nowadays, and can improve the living environment of people.

Health antibacterial. Health care antimicrobial building materials, mainly from the performance of his name, so he has some health care antibacterial function, and he is the main antibacterial effect: Ago, $\mathrm{CuO}, \mathrm{ZnO}, \mathrm{CaO}, \mathrm{MgO}$. and it is mainly through a variety of Portland to acid as a carrier to realize the. In addition, he can use the role of sunlight to comprehensively change the oxygen in the air to reactive oxygen species to achieve the role of sterilization.

Multifunctional green building materials. Multifunctional green building materials refer to the fact that building materials play a useful role in the residential environment as well as the carrier of their buildings. First, the new tile can inhibit the emergence of miscellaneous bacteria and prevent mildew. 
Second, green building materials can adjust the indoor temperature, and some wall tiles can play the role of regulating indoor temperature.

\section{Scope of new materials for building energy efficiency}

\section{New energy-saving materials should be chosen when building roofs}

Usually, when the project is being carried out, it is necessary to place the thermal insulation material with good thermal conductivity, water absorption and small volume to the roof board and the waterproof interlayer between the two, so that it can become insulation. So, the general should be selected with strong heat preservation ability and can also reduce the energy consumption of new materials, such as cement polystyrene board of this kind of plate style material, in addition to the selection of expanded perlite like loose material. Finally, but also to the waterproof layer arranged on the insulating layer, so not only can protect the, can also facilitate inspection repair, but it may have a relatively high demand for funds, it is not widely.

\section{New materials for energy saving are selected for building walls}

In the past, many walls of old buildings were made of concrete and stone, which not only had poor heat preservation function, but also increased energy consumption. The new energy-saving materials for wall materials have good thermal insulation function, including molded polystyrene, foam board and so on. Now we say this kind of organic insulation material has been widely used in the city building, and its extensive range, but this requires the implementation of the project construction process of new employees to master. Now there is a new material developed in building energy saving, environmentally friendly flame retardant honeycomb composite wall material that is new, it is the use of renewable energy, its main principle is to waste such as straw and cinder with cement mixing and compression formed by doping. The new building materials mentioned above has obvious advantages, is conducive to the city of green environmental protection, reduce waste emissions, using the correct number of reinforced concrete and there is not much use, need to consume less energy, which can be widely used for its range.

\section{Use new energy saving materials in building doors and windows}

From the outside to the house is completely two different worlds, especially in the hot summer or cold winter, so the energy saving of doors and windows is of great significance in the green building, which is worth the extensive attention of the construction industry. In order to achieve energy saving and environmental protection in the building doors and windows, it is necessary to improve the glass and frame joints as well as the tight degree of the overlap of the doors, windows, frames and fans. Only when the connections are very tight, can the air circulation be reduced. First of all, in the installation of doors and windows must be reserved hole, must not be allowed to install the side side stone mouth, or is installed first and then build a port; design of doors and windows as much as possible to increase the opening gap of the overlap of it so as to reduce the opening gap width; in order to ensure the rigor of the doors and windows, gap junction outside the doors and windows of the surrounding wall and to use this kind of polyurethane materials, can not use cement or mortar; if the metal frame of the doors and windows, to use rubber, plastics and other materials with heat insulation function Bridge treatment, but to ensure that its width and length, but also to ensure the destruction of bridge in time can not be installed accessories however, the premise is to ensure that the processing of metal frame windows and doors have enough space.

\section{Other aspects of energy-saving applications}

The main body of modern architecture is the combination of steel and concrete structures. Because the steel structure can guarantee the safety and soundness of the building, and the steel structure can be recycled two times when the building is recycled, so it is a kind of energy saving. Therefore, in the future construction process, we should vigorously promote the steel structure, so that the steel structure gradually banned the traditional steel mixing structure. Increasing the strength of reinforced concrete structure and strengthening the durability of reinforced concrete can effectively prolong the service life of buildings, so as to achieve the desired energy saving effect. When the summer high 
temperature hot weather, we can still use the building shading measures so as to make building energy-saving effect, this method is a good method to reduce the energy consumption of the natural contrast, is more economical and practical.

\section{Application and development of energy saving materials in modern architecture}

The application of energy-saving materials in construction should maximize resource conservation, minimize environmental impact, and take health as the core, moderate and comfortable, and realize the harmonious and unified construction of "people, nature and architecture" of the three.

\section{Make full use of renewable resources to achieve building energy efficiency}

Due to the limited resources of our country, the effective use of renewable resources is even more important. At present, the only solid waste product of stock has been more than 200 million tons, the serious pollution of the environment, and the construction industry to link energy consumption pressure, will increase the use of these waste research, which can reduce the pressure on the environment, beautify the environment, but also can shoot two hawks with one arrow. At the same time, it can also promote the further development of building energy conservation and greening in china.

\section{Promote the development of energy-saving materials}

Comprehensively carry out material innovation, technological innovation, and promote the development of energy-saving materials. At the same time, the development of energy-saving materials also need to further strengthen the cooperation, to develop and implement strict regulations and management of building energy-saving materials into application in solving problems in all aspects of the development process of energy-saving materials in scientific research, production, design and construction, promote the development of environmentally friendly building materials market.

\section{Promote the large-scale application of energy-saving materials in construction, and promote the structural adjustment of building energy consumption}

Do a good job of energy-saving materials in the construction of large-scale application demonstration projects, expand the demonstration scale, strengthen demonstration project management, to ensure the smooth implementation of demonstration projects, to achieve the expected energy-saving benefits. Improve energy-saving materials application technology standards, carry out energy-saving materials application, construction industry demonstration work, to promote the development of the entire construction industry, and promote the structural adjustment of energy use.

\section{Concluding remarks}

Green building materials can drive a lot of energy saving benefits. We find that green building materials can be manufactured in a variety of materials during the manufacturing process, and these materials are very inexpensive and easy to obtain. For example, we can use some agricultural production materials to reduce the pollution of agriculture, the pollution of the environment and the damage to vegetation. Not only that, but also in the protection of the environment at the same time, the production of building materials for the benefit of people's quality of construction life. In addition, we found that there are a lot of construction waste in our daily life, the construction waste is an unreasonable accumulation in our lives, because of the construction waste basically for our life is of no value any, and green building materials can be found in these construction waste recovery and utilization, energy saving is a good means of rational use of resources. To sum up, with the development and progress of science and technology, intelligent green building materials will also be rapid development and progress, and the scope of application will be more broad. 


\section{References}

[1] Wei pengfei. Application of new materials and technologies for building energy saving [J]. science and technology innovation, 2012 (12): 125 -125.

[2] Kang Ming, Zhang Hao. Discussion on the application of environmental protection and energy saving design in green building [J]. Building materials and decoration (early part). Marketing, 2010.4 (10): 23 - 24.

[3] Liu Jie, Du Xinling. Talking about environmental skill design in green building design [J]. Building materials and decoration (late), 2011, 6 (06): 37 - 39.

[4] Liu Jie. Application of new technology and new material in residential design [J]. building energy conservation, 2011 (5): 19 -20. 